\title{
THE IMPORTANCE OF TIME MANAGEMENT FOR THE SUCCESSFUL OF TEENAGERS' IN EDUCATION: AN OVERVIEW
}

\author{
Amuta Arumugam ${ }^{1}$, Dr.Ganesan Shanmugavelu, $\mathbf{P h D}^{2}$
}

\author{
Dr.Fauziah Hanim Bt.Md Yusof, PhD $^{3}$, Dr.Munirah Bt.Abd Hamid, PhD $^{4}$
}

Dr.M. Nadarajan Manickam, PhD $^{5}$, Dr.Kamaruddin Ilias, PhD $^{6}$

\author{
Jagdave Singh Avtar Singh ${ }^{7}$ \\ ${ }^{I}$ Certified Counsellor, Ipoh, Perak, Malaysia \\ ${ }^{2}$ Senior Lecturer, Institute of Teacher Education Ipoh Campus,Malaysia \\ ${ }^{3}$ Senior Lecturer, Institute of Teacher Education Ipoh Campus, Malaysia \\ ${ }^{4}$ Senior Lecturer, Institute of Teacher Education Ipoh Campus, Malaysia \\ ${ }^{5}$ Senior Lecturer, Institute of Teacher Education Keningau Campus, Malaysia \\ ${ }^{6}$ Senior Lecturer, Institute of Teacher Education Ipoh Campus, Malaysia \\ ${ }^{7}$ Principal, Sierramas Secondary School, Selangor, Malaysia
}

Article DOI: https://doi.org/10.36713/epra8291

DOI No: 10.36713/epra8291

\begin{abstract}
This study examined the dynamic relationship between the time management skills and the that impact on teenagers' academic achievement. Time management is the key valuable factor and it may actually affect individual's overall performance and achievements. However, all of these are related by how individuals manage their time to suit their daily living or to make it flow steadily with their routines. Encouraging settings and environment will surely promote positive outcomes to teenager, besides having good lectures. Nevertheless, good time management is vital for teenagers to shine, however, some of the teens do not have good time management skills that have negatively affected their lives and their academics. The usage of time by teenagers in higher education institutions is related to their daily routines and activities. Their time management can also affect stress levels as they need to cope with their tasks and their personal achievements. In this regard, the hypothesis was analysed that how effectively, they are managing their time for achieving their academic standards. Meanwhile, there were significant factor in behaviour and attitude impact in time management into positively related to academic achievement of teenager although the relationship is weak. Time planning is the most significant correlated predictor.
\end{abstract}

KEYWORDS : Time Management, Strategy, Teenager, Successful, Attitude, Education

\section{INTRODUCTION}

Time is a priceless resource and continues to pass by without coming back therefore, the secret to achieve success in life is effectively managing this resource that everyone possesses equally and paying sufficient emphasis to plan. Time management is an important tool and capabilities that brought to solve any problem to achieve any success or to have the maximum benefits after putting in minimum inputs. Among modern era, time is very precious and its proper management of time is the key to success. The high performance required by competitive conditions forces teenagers to use time effectively and stipulates the search to control time. The challenging environment explores nowadays that encourages people to plan and manage time effectively as early as to start from their elementary education. Surprisingly, the term "time management" became familiar in the 1950's and 1960's as referring to a tool to help people make better use of available time. The strategy defined time management as selfmanagement with an explicit focus on time in 
deciding what to do, on how much time to allocate to activities, on how activities can be done more efficiently and when the time is right for precise activities. The analyst defined that time management as "behaviours" that aim to achieve an effective use of time while performing certain goal-directed activities. Potentially they were three surfaces of time management behaviours which are short range planning, long range planning and time attitudes. Short-range planning strategy performs to encompass a variety of items that require planning in the short run, either within the day or within the week.

Time attitudes are more attitudinal in nature. Long range planning competence is to handle everyday tasks over a longer time perspective by keeping follow of significant dates and setting objectives by putting adjournment. To each one these behaviours of time management emerge to have obvious and straightforward meaning for effective performance. Thus, academic performance is measures ability and achievement level of a learner in academic, subject or particular skills. On the other hand, mostly they often complaint doesn't have enough time to complete all the tasks assigned to them even trying to read all the books and chapters assigned, meet paper deadlines, and participate in extracurricular activities. Hence, they become overwhelmed with feelings that there is not enough time to complete all their work adequately.

Time is a priceless resource and continues to pass by without coming back. The secret to achieve success in life is effectively managing this resource that everyone possesses equally and paying sufficient emphasis to plan [1]. The high performance required by competitive conditions forces organizations and directors to use time effectively and stipulates the search to control time [2]. The rival environment nowadays encourages people to plan and manage time effectively as early as to start from their elementary education.

The term "time management" became familiar in the 1950's and 1960's as referring to a tool to help managers make better use of available time. The concept of time management comes from Frederick Winslow Taylor for early analysis of motion and time studies of workers with purpose to reduce unproductive work tasks and time wasting. [3] defined time management as self-management with an explicit focus on time in deciding what to do; on how much time to allocate to activities; on how activities can be done more efficiently and on when the time is right for particular activities [3].[4] defined time management as "behaviours" that aim to achieve an effective use of time while performing certain goal-directed activities. There are basically three surfaces of time management behaviours which are short range planning, long range planning and time attitudes [5]. Short-range planning appears to encompass a variety of items that require planning in the short run, either within the day or within the week.

The aim of this study is to determine the relationship between the time management and academic achievement of the teenagers. The analysis identified an important element result as showed in three main factors associated with time management, which can be classified as time planning, time attitudes and time wasting. Time management is a skill that everyone should not only know, but also apply perhaps most teenagers complain about running out of time when asked to do a certain task, perhaps they develop frustrated because they are not able to make it before the deadline. Time management is extremely important, especially when it comes to the higher level of academy because it will boost their grades and enhance their productivity (Laurie \& Hellsten, 2002). However, most of the time they face problems like task aversion and uncertainty, so they start to procrastinate because they lack organizational skills. As a result, they will not be able to organize duties according to their priorities, so they get distracted easily, ending up delay. As we can see, time management is quite essential to anyone and it is one of the keys to higher academic achieving (Kelly, 2004).

An important element among these strategies is the introduction of academic studies focusing on the relation to time management that review academic achievements. The related showed that the time management attitude and skill levels of teenagers and the effects of these skills on their academic achievement. The research revealed that a majority teenager possesses moderate level time management skills and only a significantly small portion has high level time management skills (Yilmaz, Yoncalik \& Bektaş, 2006). This also emphasizes teenagers should start to acquire time management senses on their own reading materials on the issue or via the framework of psychological counselling and guidance studies applied in academic and adopt effective time management attitudes techniques to determine how and where they spend their time (Lisa \& Robert, 2008). This includes the nurturing of time management competencies practices have been proven to be some of the top indicators toward achieving a high level of academic success and performance. Various studies showed that time management practices serve for many purposes, not only for challenging the performance of the teenagers, but the practices show the way not only to a top level of academic performance, but to good physical condition and lower levels of stress. The important purpose of the present study was educational competency, using time managing techniques, test pressure, and test proficiency (Faisal, Miqdadi, Abdulla \& Mohammad, 2014). 


\section{Dimensions of Time Management}

The effectual utilizing time managing requires procedures to ensure the quality of planning behaviours factor in teenager lifespan. One can make use of time effectively and competently by keeping time logs, setting immediate longstanding goals, prioritizing responsibilities, constructing to-do-lists, arrangement and organize with their study place environment (Sabelis, 2001). Time saving techniques and behaviours can be categorized into numerous groups and be liable to contribute to a number of fundamental qualities in general. There are three surfaces of time management behaviours such as short-range planning, long- range planning and time attitudes (Laurie \& Hellsten, 2002). However, short-range planning is the capability to set out and systematize responsibilities in the short period of time whereby long-range planning competence is to handle everyday jobs over a longer time perspective by keeping follow of significant dates and setting objectives by putting adjournment (Alay \& Koçak, 2003) and finally, time management in attitudes demands a key shift in emphasis concentrate on results.

\section{Long Range Planning}

Long-range planning means to have longrange objectives and having disciplined routines for self-organization and it is comparable to long range planning. Meaning to acquire a summary of the everyday jobs that necessitate to be executed, time limits and priorities which increase the perception of having control over time so, this may enable planning to deal with all activities (Kelly, 2004). Hence, directly have less perception of control over time because it may be tackling to be familiar with how much effort requires to be completed within hours, days or weeks, it may even be the immediate measurable effect of planning. This contributes the impression to indicate that time management practices accomplish to have an influence on educational achievement, but that's not all they affect (Brigitte et al., 2005). The competence found that the teenagers had advanced overall academic achievements who accounted using goal-oriented time management practices.

\section{i. Short Range Planning}

This short-range planning explained time management activities surrounded by daily or weekly time structure and cover the activities such as setting objectives at the commencement of the day, planning, focus on daily behaviours and creation work contents (Yilmaz et al., 2006). Basically, shortrange planning behaviour, forecasting of time in the short run, surrounded by the time enclose of a week or less, established a constructive relationship to grade point average. It is a type of planning interface with accomplishment that associated with dealing performance as well (Noftle et al., 2007). Likewise, most of the studies determined control for teenager time managing and determining the total time committed to the course whereby academic achievement means the educational objective that is accomplished by them over a short period (Lisa \& Robert, 2008). In this research found it has been demonstrated that there exists a positive significant relation between their grade point averages, time attitudes and short-range planning.

\section{ii. Time Attitude}

Time attitude emphasis key concentration on results, not on being busy. There are a lot of cases with teenagers who waste their lives in discoloured by placing their self into incorrect responsibilities or weakening to focus their activity successfully in established time management that directly affect the collective of academic achievements (Mercanlioglu, 2010). The awareness view on how their time requires to be used up or planning, including utilizing short and long period goals and time attitudes or accomplished both planning encouragement. Attitudes may initiate that they had much more time to finish their everyday jobs because they experience more in control of how their time was exhausted, therefore, aware when they had to state no to activities (Kaushar, 2013). About time management practice that connected with individual's awareness, attitudes and is comparable the perception of having control over time. Therefore, time attitudes comprise the insight of the individual in control of time, the observation that the person is efficiently managing their time and awareness that the teenagers making constructive utilization of time (Karim et al., 2015).

\section{Key Planning in Time Management Strategies}

Time management develops important intellectual and decision-making qualities in life skill, but it is something that is rarely taught within the academy curriculum. Occasionally, the challenge teenager facing here is understanding even the basic organizing and prioritizing time could help them become so much better equipped for adult life. Obviously, many teenagers struggle with time management, but the good news is that with a bit of commitment and discipline, the skill of time management can be learned, developed and utilised quite easily. While teenager involves think it's fine to wait until the last possible, finally to complete their responsibilities or project becoming lifelong procrastinators that create a big problem later in life. And these might be considered to be aspects about waiting until the last possible minute to get things that could cause problems ranging from high-stress levels to relationship trouble. In a general view, it is important to teach teenagers how to behave 
responsibly, meaning is managing their time wisely without requiring constant reminders or assistance to get work done.

a. Time Tracking Worksheet - This worksheet helps track activities and it features a column for the estimated duration of each task, and another column for recording the actual time that spent on the activity.

b. Time Management Wheel - This editable and printable time management wheel allows colour code the activities for the day. It features one-hour intervals on its time block and the creator suggests assigning a particular colour to a specific task and then placing a piece of sticker in the corresponding time when doing that activity.

c. Time Management Log - It is a learned skill, and the right tools can help accomplish more within the allocated time for specific activities such tool called Eisenhower Matrix. It is proven to help manage time more effectively, how the matrix can be used in identifying a task's level of priority by a letter coding helps classify an activity level of importance: (important, somewhat important, not important and urgent)

d. Time Log Sheet - This column time tracker has sufficient space to record activities and allows to track the amount of time spend on every activity list down. As fill in this form, then teenagers able to know when to start and when to finish an activity, as well as the total time spent on it. The template also prompts to identify if an activity is something intended to do or if it was done at the spur of the moment. The advantage of having a tracker like this is that, over a certain period, this will be able to see a pattern of how the use of time, perhaps something enriches or time spend a huge chunk of the day on time sink activities like excessive social media use.

It may take a bit of time and a bit of experimentation to find exactly what suits and preferred method of working the time management to ensure actual strategy adoption and don't just try and wing it all the time. An effective time management strategy needs to be:

\footnotetext{
i. easy to plan

ii. easy to implement

iii. easy to maintain better decision-making skills,

iv. better performance

v. increased responsibility and independence

vi. more opportunities to relax and unwind

vii. more time for family and friends

viii. reduced anxiety when projects are due or test dates are approaching
}

Design of Hypothesis Structure.

The objective of this examine drew several prior to the hypothesis that measure various time-related constructs information, Bond and Feather (1988), on the psychological effects of teenagers to assess which individuals distinguish their use of time to be structured and purposive" (Feather \& Bond, 1983, p. 321).

a) Time Planning.

- Do you have a set of goals for each week ready at the beginning of the week?

- Do you spend time each day planning?

- Do you make a list of the things that have to do each day?

- Do you make the schedule of activities that have to do on schooldays/workdays?

- $\quad$ Do you have a strong idea of what you want to accomplish during the next week?

- Do you have set goals for the entire quarter/semester?

- Do you clip of Xerox articles which, although not presently important to you, may be in the future? do you think can usually accomplish all goals for a given week?

b) Time Attitudes.

- When you have various responsibility to do, do you think it is best to do a little bit of work on each one?

- Do you establish deadlines for completing work?

- Do you try to schedule best hours for most demanding work?

- Do you keep important dates such as exam dates, research paper due dates, and others on a single calendar?

- Do you set and honour priorities?

- Do you confident that there is room for improvement in the way manage your time?

- $\quad$ Are you able to make minor choice quickly?

- $\quad$ Do you usually keep desk clear of everything other than what are currently working on?

c) Time Wasting.

- Respectively in a week do you do things as they naturally occur, without an effort to make a plan in advance and compulsively?

- How frequently you find doing things which interfere with academic work is simply because hate to say "no" to people?

- Do you find yourself waiting a lot without anything to do?

- Do you continue unprofitable routines or activities? 
Analyse and interpret data information.

It is encouraged to know that teenagers can perform well, still have some way to go before they can be said to be truly innovative. Being able to creatively solve problems that have already been identified, one thing being innovative by identifying new problems to solve through seeing issues from multiple perspectives is quite another. This research ability to identify problems and define them in new ways is a fundamental skill in design their behaviour and attitude thinking. Therefore, design thinking in time management may just be the key to unlocking the innovative potential. So, to perfect and extend the design capabilities by constantly challenging and pushing at limitations. This has not always worked out well, but behaviour and attitude commitment to improve may just be what is required to curb exercise teenagers reframing in time design instincts.

\section{Key Strategies in Implementation.}

Time management for teenagers and everyone else is about being purposeful with day. It's about taking control of what time and optimizing it for productivity, focus, and above all, balance. To really optimize time and get ahead on projects, need to be more tactical to master the time management:

\section{a) Use a daily schedule template to plan the day}

Classes, seminars, and workshops might take up the majority of day, but how schedule their own time can make all the difference and creating a to-do list, it's more important to master schedule. To-do list only tells what like to do. A schedule tells when going to do it and having a daily schedule template in place puts in control will help stay organized, focused on what matters most, and even help overcome procrastination.

\section{b) Understand how current spending time and where the losing part}

Basically, schedule will give an ideal version of daily day schedule, but in order to build better time management habits, the major things need to know how you're actually spending your time. Without a clear understanding of where time goes each day, it's impossible to build better time management strategies and stay focused. When it comes to tracking time, below have two options will help to close some of gaps:

\section{c) Set proper goals to measure the progress} Spend a day or two writing a "time log" manually tracking how time spend each moment of the day.Practice with free tool like "RescueTime" automatic time-tracking, distraction blocking, and more exactly where time goes, get powerful reports and tools to improve every aspect of day. "RescueTime", provide a clear breakdown of what apps, websites, and tools that organized each day by category and productivity score.

Goals are a great way to get motivated to do assignment work. Unfortunately, the way most sets goals that completely wrong. The issue being raised that goals is just the end result. They don't tell anything about how we're going to achieve them rather than starting at the goal and working backward, focus on what needs to get done to hit and surpass that goal. The point here is maintaining high visibility, focus on consistent progress and building better habits. From this perspective, daily progress will help motivate to do more and looked into all the things that can boost mood and motivation, "the single most important is making progress on meaningful work."

\section{d) Break large projects into small and actionable tasks}

Part of proper goal setting is being able to break large goals down into daily tasks. Not only does this keep teen focused, but it can even help stop procrastinating. Although easy to procrastinate when a project feels like such a huge task. However, taking that first step is usually all need to build momentum. The concept of time management expert is the best thing can start resolve from smallest that most doable follow next step is on a big project and then list out with a deadline for each project into a few steps. Each step is doable and can be scheduled into the daily organize timetable rather than feeling overwhelmed in end goal. Another example using "RescueTime", set daily goals to spend 3 hours writing, meaning focus on making progress.

\section{e) Take a break at the right time}

One of the best ways to maintain productivity over time is to take more breaks. Subsequently, doing a lot of tasks without a break, it is harder to stay focused and motivated. Allow some downtime between tasks to refresh yourself. In this scenario, consider grabbing a brief nap, going for a short walk, or meditating. According to psychological wellbeing our minds naturally crave breaks after every 90 minutes of intense work. Even if don't keep a timer, automatically the body will tell when need a break by becoming hungry, sleepy, fidgeting, or losing focus. When starting to feel this way, it's time to take a break. 


\section{f) Optimize study time for only do one thing at a time}

It's tempting to think that can do multitask when schedule is crammed, but the more teenager tries to do at once, the longer everything takes. Instead, studies have found that deeply focusing on a single task at a time can be up to $100 \%$ more productive. While, reflecting to "singletasking" like this isn't easy, if have a hard time focusing on just one thing, by removing distractions, including phone, start small and set a timer even five minutes of distraction free work time is beneficial and finally take a break in between each session.

\section{g) Build better habits and routines for long term success}

The best time management strategy for teens and everyone else is simply to develop habits and routines that promote the kind of actions that want to do more of. By practicing good housekeeping methodology such as $5 \mathrm{~S}$ will keep organized and will help save precious time. 5S, a Japanese methodology consists of 5 steps in order, starting each with "S", "Seiri", "Seiton", "Seiso", "Seiketsu" and "Shitsuke", which means, set everything in order, identify and tag everything, keep everything clean, practice the above each day and finally standardize the above as daily routine in a disciplined manner. Keeping everything organized and clean will save time to access resources, whenever need those urgently. Hence won't waste time searching the required stuff.

\section{h) Eat the Frog Tools and Technique}

Eat the frog is a method designed to help tackle the biggest, most difficult task first thing (and no consumption of amphibians required). This technique is a method that aims to overcome procrastination, a habit that most are guilty of and wish to conquer. How this works is that by prioritize "frog" at the top of the list. The idea behind this technique is that once have most dreaded task out of the way, it will get the ball running and set the flow for the rest of the day. By producing a matrix of need versus want, this can categorize tasks into four groups:

1. Things you have to do, and don't want to do

2. Things you have to do, and want to do

3. Things you don't have to do, and want to do

4. Things you don't have to do, and don't want to do

Basically, this technique aims to help overcome biggest task complete first and imagine the sense of relief and accomplishment thus, it will make the rest of the tasks seem effortless.

\section{i) Getting Things Done}

There is a strong practice in Getting Things Done, or GTD, is a framework for organizing and tracking tasks created by David Allen. The method propels to add context and structure to tasks so that has a higher chance of actually completing them. The idea behind GTD is that because "your mind is for having ideas and not holding them" the method provides a way to turn ideas into actions, and gives a clear list of what have to do. GTD involves following 5 steps workflow:

i. Capture: write down all the ideas on a list (the 'inbox').

ii. Clarify: process the ideas.

iii. Organize: determine which ideas can take action on.

iv. Reflect: assess the list on a weekly basis so that it doesn't pile up!

v. Engage: once the ideas have been captured and processed, and start knocking things off the list

If tasks take more than one step to complete, then it should be considered a project. If the list has more than one related task, group them together and create a project. GTD provides a system to tick off the tasks of to-do list. The concept is designed so that once teenager develops a system that can rely on, which will then free up brain-power for doing more productive things will get done.

\section{Benefits of Time Management}

There are piles of benefits, why time management is very important that increased a sense of wellbeing, prioritizing time and huge increases in productivity. By managing the time or even understanding what spends time on and equipped to make changes to be more effective at whatever it is aim to achieve. The point is how can improve selfproductivity to manage and focus the time management in a proper control of time comes less stress that helps become more clearer about own goals. However, some of them has negatively affected their life and their academics that related daily routines and activities. A teenager can also affect stress level as they need to cope with their tasks and their personal achievements. The road to success in social life passes through effective and efficient which is only possible via time management. Today encourages teenager from as early as their elementary education to plan and manage time effectively is necessity of time planning (Alay \& Koçak, 2003). How crucial time management is? Knowing how to manage your time well transferable skill that will not only get through academy levels, but it's something can benefit throughout life to maintain a healthy lifestyle. 


\section{a. Become more Organised}

The important part of time management is planning, which helps to stay on top of all assignments, exams, and study times. Also, schedule the time day by day and right down to the hour by hour for a more detailed schedule. This gives an overview of everything need to do and how will accomplish it. This will give self-confident peace of mind and will help to enjoy studying, and habitual benefit in the studies.

\section{b. Build a good Reputation}

When have good time management skills, they able to honour meet deadlines. When do these things, it will be known for being reliable. Showing that by having a good time management skill helps to build a good reputation and shows that can be trusted with responsibility.

\section{c. Become more Focused}

Time management can provide relief from stress resulting from procrastination or falling behind with academic work. Good time management skills can help become focused, can help become an effective learner, and can help avoid constantly feeling as though have too little time. Proper time management assists will tackle the tasks in a timely manner, and this will facilitate people focus better on the task without feeling stressed. Managing your time properly also allows to concentrate on one task at a time, instead of trying to get everything done at once. When focused, will increase the delivery of quality work, able to set goals, plan for how will reach them, and capable to achieve all the goals effectively. Focus is an important trait that can use in future, too.

\section{d. Improved decision-making ability}

Whether relying on a time-chunking technique or discover the power of list-making, side of benefit of good time management skills is the ability to make better decisions. When feel pressed for time and have to make a decision, but more likely to jump to conclusions without fully considering every option. Through effective time management, eliminate the pressure that comes from feeling is not enough time. Perhaps will start to feel calmer, relief, and in control when the time comes to examine options and make a decision, instead of rushing through the process and take an opportune time to carefully consider each option.

\section{e. Reduce Stress}

When there is control of time, it's easy to end up feeling rushed and overwhelmed and when that happens, it can be hard to figure out how long it's going to take to complete a task. Think of a time when to miss a deadline and were frantically trying to finish the project. Once learn how to manage the time, therefore no longer subject to that level of stress. Besides, it is better to have a clearer picture of the demands on the time. This may able to estimate how long a given task will take to complete, and know meet the deadline.

\section{f. Self-discipline is valuable}

When practice good time management, this may leave no room for procrastination. The better get at it, the more self-discipline may learn. This is a valuable skill that will begin to impact other areas of life where a lack of discipline has kept from achieving a goal.

\section{g. Effective Time Management boosts an} individual's morale and makes confident

As a result of Time Management, individual tasks accomplish within the stipulated time frame, making them popular in their group as well as amongst their peers. People who recognize the value of time are the ones who manage to stand apart from the crowd. Individuals who finish their task on time are looked up to by others and are always the centre of attention everywhere.

Things to Remember:

- Control time instead of it controlling you.

- Postponement usually takes more energy in the long run than just doing it.

- Recognize the limitations, there are only 24 hours in a day and we cannot do everything, so pick what matters most and spend time doing it.

- Remember life goals, they can provide motivation and help prioritize.

- Reward for accomplishments.

- Pay continual attention to balance of work.

\section{The Importance of Guidance \& Counselling in Teenager's Life}

Guidance and counselling are important for teenager as a huge role in bringing out the best in their lifestyle improvement. Basically, therapist will need guidance to polish their personality and given advice on how to manage and deal with emotional conflict and personal problems. In this view a proper counselling will help incorporate valuable lessons in their daily life. Before starting any component of the task, set clear expectations for behaviour. These may seem like standard expectations, but clearly stating them before can help eliminate small missteps for who need reminders. Counselling is designed to facilitate teenager's achievement, improve behaviour, attendance, increase their skills and help them develop socially. Helping teenagers figure out how to manage their time can be tough, and there's no 
one-size-fits-all solution to the problem. No matter where they are in the education process and understanding time management style based on their personality type is key to succeed long-term. The person who doesn't learn time management skills are at risk of becoming lifelong procrastinators. In that case waiting until the last possible minute to get things could cause problems ranging from high-stress levels to relationship trouble. It's important to teach teenagers how to behave responsibly. That means managing their time wisely without requiring constant reminders or assistance getting work done. The perks of good time management include:

- $\quad$ Better decision-making skills

- Better performance in academics

- Increased responsibility and independence

- $\quad$ More opportunities to relax and unwind

- $\quad$ More time for family and friends

- $\quad$ Reduced anxiety when projects are due or test dates are approaching

\section{a) Teaching Time Management Skills}

Basically, teenagers have fairly structured schedules, as a result, many of them don't learn how to manage their time wisely when they have some downtime. While it may look good transcripts to say they're the captain of the soccer team and head of the council, for some teens, a busy schedule can be problematic. The lack of free time may eventually take a serious toll on their physical and emotional health Mahoney JL, Vest AE. 2012. It's important to find just the right balance for teenagers, but it's also important to make sure they aren't burning themselves out as they run around from one activity to the next. Well to be too idle, a little downtime is really good for them. It also highlights the challenges and learning experiences start by helping teenager understand their own unique rhythms and be specific able to be more productive than others. Helping teenagers critically analyse and reflect on the main learning points of their own productive periods is more effective than parents deciding when teenagers should do what. The interest part is letting them be in charge the key success for time management.

\section{b) Irrational Belief about Time Management}

Therapist can help teenagers develop an appropriate framework for boundaries. Handling time to accomplish goals can be challenging for even highly successful people. It is important to consider how teenagers work best, and even to seek assistance from others, struggling to meet deadlines and balance work, college, and life demands. Boundary work honours self-esteem and self-worth thus, learning these useful skills during the teenage years can position for ongoing success and happiness in the future. Therapist helps teenagers recognize the root causes that trigger negative beliefs. After gaining more awareness, they can also learn new ways of thinking and behaving. Over time, therapist can teach teenagers how to accept and even embrace themselves.

\section{c) Beating procrastination}

In terms of procrastination, or putting off tasks which need to be done, is a major challenge of time management that can have a major impact on levels of stress and anxiety. However, relatively a simple time-wasting or laziness, procrastination is a genuine psychological response to workload demands, and is particularly common at university. The challenges here is expand the irrational delay that has negative consequences for the procrastinating individual, procrastination is a habitual form of postponing action to a later date. Procrastination happens at different times for different people, and depends on struggle situation to convert the intentions into actions. Therapist will help to identify the of quality time management is perhaps the single most important and challenging skill to develop as a student. In an environment in which nobody will hold their hand, or tell precisely what should be doing and when, the art of managing and meeting personal deadlines must be mastered sooner rather than later.

\section{d) Talk About How to Manage Stress}

The influencing can be so overwhelming, high levels of stress are not helpful when it comes to managing time effectively. There are two basic kinds of stress such as internal and external. Basically, in this case the internal stress is self-imposed ("I need to straight As!"). Whereby, challenges in external stress of the result of deadlines and other pressures ("I have a math test tomorrow!"). Despite through selforientation structures if teenager is feeling too much external stress, see if he can remedy the situation by starting projects and other assignments earlier, asking lecturers for extensions, or dropping extracurricular activities. If teenager is the type to put a lot of internal pressure on himself, then look for ways to help him keep a healthy perspective on what's important and what's not. 


\section{e) Compartmentalize work time}

Research shows that teenagers who actively strategize about how they are going to study actually improve their performance on tests. Therapist will encourage teens to use a written planner. They should write out everything they need to do for college, sports, extracurricular activities, or family obligations all in one place. Besides learning framework using the Pomodoro method that's working for 25 minutes followed by a five-minute rest break (to get up, walk around, use the bathroom) can make work seem less daunting. Also, having teens do their work outside of their bedrooms provides a natural boundary between work and rest.

\section{f) Structure of self-regulation}

The assessments of learning are relevant and robust in these changing times to enhance learning teenagers care a great deal about socialization, and the fear of missing out (FOMO) can make it difficult to self-regulate or prioritize sleep. Screen management apps like Moment and Forrest can promote self-awareness and mono-tasking by creating natural boundaries. Thus, not texting after a certain time at night, for instance, and requiring phones to be on chargers outside the bedroom. The endorsement in self-regulation and, will teenager think about what strategies make them more productive. Whereby, turning off their phone and putting it in the other room, disabling messaging on their tablet, or creating dual screens work and social on their computer that allow the chance to navigate and identify potential solutions.

\section{Benefits of Guidance and Counselling}

There is a simple secret how to get teenagers excited to become more organized and better manage their time. The therapist encourages them to identify personal goals and ask them to dream about how they would spend all the extra hours they will gain by being more organized. Hence, they become naturally more motivated. However, time management all boils down to the way use your time each day. More or less people seem to have a natural knack for knowing how doing this, but the truth is, it's something that everyone is able to do. Basically, either let the day control you or you can make a plan to control the day and do this by managing the time that are given. Meaning high achievers seem to get so much done when there are other people who seem to accomplish nothing in a day given the same amount of time. Following are some of the benefits that teenagers get from effective guidance \& counselling:

i. Teenagers are given proper guidance on how to deal with psychological problems which can badly impact their studies. Through these sessions, their able to develop certain problem-solving skills which to an extent help them deal with particular issues surrounding their lives.

ii. Teenagers are advised on how to cope with different situations they tend to face in their academic life. Basic advice will be enhancing them perspective on how should they behave in certain scenarios.

iii. It helps to shape their behaviour and also instil enough discipline in them. Proper guidance helps them achieve their goals, well guided \& counselled in a way they know what to do and how to do things in the best possible way.

iv. It allows teenagers to talk to teachers about various experiences that make them uncomfortable. Thus, they can openly share problems that they cannot share with their parents.

v. Talks related to alcohol, drugs, personal feelings or any kind of abuse, can be openly discussed. Guidance and counselling also make teenager better human beings since they are counselled on how to act and behave in a particular situation

vi. It enables teenagers undergoing certain difficulties in their lives, to ask questions and clarify them through guiding and counselling. Finally, counselling helps them ask without any fear since the person in charge is willing to help.

\section{CONCLUSION}

This study influences the relationship between the time management that impact academic achievement of the teenagers. First, knowledge of the factors influencing poor academic achievement that factor time management concept allows one to predict those who will, and those who will not, do well in an academic program. Second, an understanding of time management relations among ability, motivation, emotional, behaviour and attitudes in the prediction of distinct components of academic performance can be used to direct towards teenager disciplines in which they are most likely to succeed. Finally, knowledge of the factors influencing academic achievement enables to develop fair academically, those that can compensate for known weaknesses in time managing that might carry into the classroom, and those that can nurture a strength. Although there might be some days in which a teenager may not need to be so strict to his or her time management schedule, managing time well will come in handy during college. Thus, after college, having a busy career will demand the ability to manage time well. Meaning the important part is learning how to manage time can contribute to a successful life. Basically, they can manage time 
effectively when they gain an accurate understanding of how long things take including tasks.

This study also determined about how time management can help get things done, strengthen relationships as well as personal ones. People underestimate the importance of managing time effectively. When constantly feel like have to rush and don't have enough time, it's very easy to lose temper with those around. Ultimately, managing the time properly allow teenagers to rise above the level that were previously at. It opens new doors to become more organized and produce higher-quality work in academic including into goal setting, planning, prioritizing, decision-making, delegating, and scheduling. If teenager looking at increasing productivity, there's a good chance that they will need to focus on multiple areas in order to boost their time management skills. It gives an overall focus on what they are trying to accomplish, they should focus on time management because it will help lead throughout the rest of the process. Essentially, guidance and counselling are a gradual process to mould and redirect teenager for a brighter future. Along with academic development to acquire knowledge, attitudes, and interpersonal skills to set their own goals, make their own decision and take necessary decisions to achieve those goals.

\section{REFERENCES}

1. Alay, S., \& Koçak, S. (2003). Relationship between time management and academic achievement of university students. Kuram ve Uygulamada Eğitim Yönetimi Dergisi, 35, 326335.

2. Bond, M. J., \& Feather, N. T. (1988). Some correlates and purpose in the use of time. Journal of Personality and Social Psychology, 55, 321-329.

3. Britton, B. K., \& Tesser, A. (2001). Effects of time management practices on college grades.Journal of Educational Psychology, 83, 405-410.

4. Brigitte, J. C., Claessens, Eerde, W. V., Rutte, C. $G$, Roe, R. A. (2005). A review of the time management literature. Emerald Group Publishing Limited, 36 (2), 2007.

5. Brown, T., \& Wyatt, J. (2010). Design thinking for social innovation. Stanford Social Innovation Review, 8(1), 30-35.

6. Faisal, Z., Miqdadi, A. F., Mohammad, T., \& Nabil, M. (2014). The Relationship between Time Management and the Academic Performance of Students. University of Bridgeport, Bridgpeort, CT, USA.

7. Feather, N. T., \& Bond, M. J. (1983). Time structure and purposeful activity among employed and unemployed university graduates. Journal of Occupational Psychology, 56, 241254
8. Franz P. Give Teens More Downtime and Support with Time Management. The Schools TeensNeed. 2019;14(26).

9. Laurie, A., \& Hellsten, M. (2002). What Do We Know About Time Management? A Review of the Literature and a Psychometric Critique of Instruments Assessing Time Management University of Saskatchewan, Canada.

10. Lisa, M., \& Robert, M. S. (2008). I will do it tomorrow: College Teaching. 57 (5), p.21- 2154. Academic One-File, https://www.ebscohost.com[Accessed Oct 4, 2011.

11. Karim., \& Mitra, K. (2015), Time management skills impact on self-efficacy and academic performance. Journal of American Science, $7(12)$.

12. Kaushar, M. (2013). Study of Impact of Time Management on Academic Performance of CollegeStudents. Journal of Business and Management, 9 (6), P 59-60.

13. Kelly, M. (2004). Get time on your side, Careers \& Universities, 24 (4), p.28.

14. Mahoney JL, Vest AE. The Over-Scheduling Hypothesis Revisited: Intensity of Organized Activity Participation During Adolescence and Young Adult Outcomes. $J$ Res Adolesc. 2012;22(3):409-418. doi:10.1111/j.15327795.2012.00808.x

15. Matthews, G. (1999). Personality and skill: A cognitive-adaptive framework. In $P . \quad L$. Ackerman, P. C. Kyllonen, \& R. D. Roberts (Eds.), Learning and individual difference.

16. Martin, R. L. (2007). The opposable mind: Winning through integrative thinking. Boston,

17. Massachusetts: Harvard Business Press. Martin, R. L. (2009). The design of business: Why design thinking is the next competitive advantage. Boston, Massachusetts: Harvard Business Press.

18. Mercanlioglu. C. (2010), the Relationship of Time Management to Academic Performance of Master Level Students, International Journal of Business And Management Studies, 2 (1), p. 255-276.

19. 18. Noftle, E., Robins., \& Richard, W. (2007). Personality predictors of academic outcomes: Big five correlates of GPA \& SAT scores. Journal of Personality and Social Psychology, 93, 116- 130.

20. 19. Sabelis, I. (2001), "Time management: paradoxes and patterns". Time \& Society, 10, p387-400.

21. Wolfe, R. N., \& Johnson, S. D. (1995). Personality as a predictor of college performance. Educational and Psychological Measurement, 55, 177-185.

22. Yilmaz, I., Yoncalik, O., \& Bektaş, F. (2006). Relationship between the time management behavior and academic success. EJournal of New World Sciences Academy, 5(3), 187-194. 